Estudios Constitucionales, Año 12, No 1, 2014, pp. 503-526.

ISSN 07180195

Centro de Estudios Constitucionales de Chile Universidad de Talca

"El derecho de excepción y la responsabilidad del Estado: falta de servicio y acto de gobierno. Comentario de la sentencia de casación Rol No 4029-2013 de la Corte Suprema, de 24 de diciembre de 2013"

Francisco Zúníiga Urbina

\title{
EL DERECHO DE EXCEPCIÓN Y LA RESPONSABILIDAD DEL ESTADO: FALTA DE SERVICIO Y ACTO DE GOBIERNO. COMENTARIO DE LA SENTENCIA DE CASACIÓN ROL No 4029-2013 DE LA CORTE SUPREMA, DE 24 DE DICIEMBRE DE 2013* \\ THE RIGHT OF EXCEPTION AND THE STATE LIABILITY: \\ LACK OF SERVICE AND GOVERNMENT ACTS. COMMENT TO THE CASSATION JUDGEMENT No 4029-2013 OF THE SUPREME COURT, ON DECEMBER $24^{\mathrm{TH}}$ OF 2013
}

\author{
Francisco ZúNiga Urbina** \\ Universidad de Chile \\ fzuniga@zdmcabogados.cl
}

RESUMEN: Se dedujo acción civil por responsabilidad del Estado en contra del Fisco, por parte de un grupo de comerciantes de San Pedro de la Paz, a raiz de los desmanes ocurridos con ocasión de los días posteriores al terremoto de 27 de febrero. La sentencia de casación en la causa, dictada por la Corte Suprema, analiza una eventual falta de servicio en relación a la actuación de las autoridades de gobierno, al no dictar el decreto de estado de excepción en lo que los demandantes estiman tiempo oportuno. El autor comenta la sentencia de casación haciendo hincapié en los argumentos más interesantes en torno a la falta de habilitación legal del gobierno para recurrir a las Fuerzas Armadas como elemento regulador del orden público y a la fundamental diferencia, de larga data, entre los actos de gobierno y actos de administración, para efectos de hacer aplicable la falta de servicio como título de imputación de la responsabilidad del Estado.

ABSTRACT: It was deduced civil action for damages against the State, by a group of merchants of San Pedro de la Paz, in the wake of the atrocities that occurred during the days following the earthquake of February 27. The appeal judgment in the case, issued by the Supreme Court, discusses a possible lack of service in relation to the actions of government authorities, not dictate the state of emergency decree in which the applicants consider timely. The author says the cassation emphasizing the most interesting arguments about the lack of legal authorization from the government to use the military as a regulator of public order and the fundamental difference longstanding between acts of government

\footnotetext{
* Trabajo recibido el 6 de enero de 2014 y aprobado el 12 de marzo de 2014.

** Francisco Zúñiga Urbina es profesor titular de Derecho Constitucional en la Facultad de Derecho de la Universidad de Chile.
} 
and acts of administration, for the purpose of making applicable the lack of service as evidence of attribution of state liability.

PALABRAS CLAVE: Estado de excepción, Acto de gobierno, Responsabilidad del Estado.

KEY WORDS: State of exception or emergency, Government acts, State liability.

\section{LOS ANTECEDENTES}

Para este comentario resulta muy oportuna la sentencia de casación indicada por recoger dos materias propias del Derecho público: la doctrina de la falta de servicio como matriz del sistema de responsabilidad de la Administración estatal y la doctrina del acto de gobierno en conexión al derecho de excepción, reiterando la jurisprudencia una doctrina consolidada.

Sumariamente es menester consignar a continuación los antecedentes de la sentencia que se comenta. La acción a que refiere esta sentencia fue interpuesta por un grupo de comerciantes de la comuna de San Pedro de la Paz, quienes fueron víctimas, con posterioridad a la ocurrencia del terremoto de 27 de febrero de 2010, de delitos perpetrados en sus locales comerciales, específicamente destrozos y saqueos de los mismos, señalando que las fuerzas policiales estaban sobrepasadas o ausentes. En general, los demandantes explotaban locales comerciales que estaban ubicados al interior de supermercados o de centros comerciales, viéndose afectados por los saqueos que ocurrieron en esos días en tales establecimientos.

Según consigna la sentencia comentada, los demandantes estiman que en la especie ha habido falta de servicio por parte del Estado, por no haberse dispuesto de inmediato de la intervención de las Fuerzas Armadas, como lo mandaría la Constitución Política de la República, puesto que los hechos hacían indubitada la necesidad de disponer de tal medida al amparo del derecho de excepción.

Se explica en la misma sentencia que el día 27 de febrero de 2010, luego de ocurrido el terremoto, se declaró a la Región del Bío-Bío como zona de catástrofe conforme a la Ley No 16.282, designándose al intendente como coordinador y ejecutor de las medidas que correspondieran, excluyéndose a las Fuerzas Armadas de participación inmediata en el resguardo del orden público. La participación de las Fuerzas Armadas sólo tiene lugar el 1 de marzo de 2010, luego de que fuese decretado el estado de calamidad pública el día 28 de febrero.

Por tanto, para los demandantes, según se colige de la sentencia comentada y de las decisiones de primer y segundo grado, se considera que el Estado es responsable civilmente por daños, puesto que al no haber dispuesto la intervención de las Fuerzas Armadas en el restablecimiento del orden público, de forma inmediata 
a la ocurrencia del terremoto, implicó que se produjeran los saqueos de los que fueron objeto los demandantes con el perjuicio patrimonial consiguiente.

La acción entablada fue decidida mediante sentencia del Tercer Juzgado de Letras de Concepción, de fecha 31 de octubre de 2012, de causa Rol No C-81292010, en la que se rechaza la acción impetrada. Dicha sentencia del tribunal del fondo es confirmada por la sentencia de la Corte de Apelaciones de Concepción, de fecha 17 de mayo de 2013, dictada en causa Rol No 1727-2012.

\section{ReCURSO DE CASACIÓN EN EL FONDO}

El recurso de casación en el fondo, que se interpone en contra de la sentencia de la Corte de Apelaciones de Concepción, que confirma la sentencia de primera instancia, ambas rechazando la demanda interpuesta, violaría -según los recurrentes- una serie de normas legales, constitucionales e internacionales.

Así, se argumenta por los recurrentes que existe una vulneración de la Ley No 16.282 , en relación con los artículos $1^{\circ}$ y $5^{\circ}$ de la Ley No 18.575 , ya que en virtud de estas dos normas, las autoridades se encontraban facultadas para disponer la intervención inmediata de las Fuerzas Armadas, sin que existan razones para la decisión de no hacer intervenir a dichas fuerzas.

Luego, se argumenta por los recurrentes que se vulnera el artículo $9^{\circ}$ de la Ley No 10.336, puesto que se ignora el carácter vinculante de los dictámenes de la Contraloría General de la República, que expresamente había señalado, en dictamen No 42.822 de 2008, para el caso de sismo o catástrofe, en el que la autoridad estima que no procede el respectivo estado de excepción constitucional, es procedente que las Fuerzas Armadas intervengan en colaboración con los órganos de la Administración del Estado.

Finalmente, se estima por los recurrentes que se vulneran las normas constitucionales referentes a que el Estado está al servicio de la persona humana, que la soberanía encuentra límite en los derechos fundamentales de las personas y en que es deber del Estado respetar y promover tales derechos $\left(\right.$ arts. $1^{\circ}$ y $5^{\circ}$ ). En este sentido, el artículo $2^{\circ}$ del Pacto Internacional de Derechos Civiles y Políticos señala que toda persona afectada en sus derechos podrá interponer un recurso efectivo.

\section{RATIO DECIDENDI DE LA SENTENCIA DE CASACIÓN}

\subsection{Hechos fijados por la sentencia de segundo grado}

La sala constitucional de la Corte Suprema, en su sentencia, hace primeramente un resumen de los hechos que se fijaron por la sentencia recurrida, los que dicen 
relación con la existencia de una situación excepcional, como lo fue el terremoto del 27 de febrero de 2010 y la situación anormal en cuanto al orden público que ocurrió con posterioridad a ello:

"1.- El día 27 de febrero de 2010, alrededor de las 3:30 horas de la madrugada, se produjo en la Región del Bío-Bío, además de la del Maule, un terremoto grado 8.8 en la escala de Richter, que provocó un maremoto o tsunami en las costas de dichas regiones.

2.- Con posterioridad al terremoto y en las horas siguientes se empezaron a producir en toda la zona de Talcahuano, Concepción, San Pedro, Chiguayante y otras comunas aledañas, una serie de robos que ostentaron características de saqueos, realizados por turbas de personas que en grandes masas ingresaron a locales comerciales, tiendas, estaciones de servicios, a robar la mercadería y destruir tales establecimientos y también apropiarse de especies y bienes.

3.- La fuerza policial fue superada o sobrepasada en número por la multitud de personas que realizaban los saqueos, las que actuaban con violencia y también con elementos contundentes.

4.- Tales saqueos comenzaron a las pocas horas de ocurrido el terremoto y maremoto y se extendieron, al menos, hasta el lunes siguiente de acontecido éste.

5.- Se presentaba un estado de conmoción producto del megasismo, con caída total de las comunicaciones y con la fuerza policial y Carabineros dedicada, en las primeras horas, a ubicar y rescatar personas atrapadas, lesionadas y recuperar cuerpos de fallecidos.

6.- Por Decreto Supremo No 150 de 27 de febrero de 2010 se declaró a las zonas de Valparaiso, del Libertador Bernardo O'Higgins, del Maule, del Bío-Bio, de La Araucanía y Metropolitana como afectadas por la catástrofe derivada del sismo con características de terremoto ocurrido ese mismo día.

7.- Por Decreto Supremo No 153 de 28 del mismo mes se declaró el estado de excepción constitucional de catástrofe por calamidad pública en la Región del Bío-Bío por un periodo de treinta días y se designó como Jefe de Defensa Nacional para dicha región al Jefe del Comando de Operaciones Terrestres del Ejército, General de División Guillermo Ramirez Chovar".

\subsection{Fundamento de la sentencia recurrida}

Luego, se hace en la sentencia de casación un resumen detallado del fundamento de la sentencia de segunda instancia casada, que en este caso es confirmatoria de la sentencia de primera instancia, exponiéndose los motivos por los cuales se consideró que la demanda debía rechazarse, exponiéndose en el considerando tercero de la sentencia en comento, respecto del fundamento del rechazo: 
"7.- Las decisiones de la autoridad no pueden calificarse como tardías cuando se advierte que a pocas horas de acaecido el terremoto se había declarado zona de catástrofe y al día siguiente estado de excepción constitucional de catástrofe.

8.- La declaración de estado de excepción constitucional no podía adoptarse sino una vez verificados los presupuestos reales o aproximados -al menos- de la situación en la zona, relativos al orden y seguridad, sus comunicaciones, vías de acceso, número de víctimas, edificios destruidos, efectivos policiales y Carabineros disponibles, etc. Por implicar una restricción de derechos y libertades personales la decisión no puede ser apresurada, sino que se impone que sea evaluada, ponderada y coordinada.

9.- La mera existencia de un poder o atribución que le corresponde ejercer al Presidente de la República no resulta suficiente para atribuirle responsabilidad en un evento en el cual ninguno de sus órganos o dependencias tuvo participación, toda vez que no parece razonable pretender que su responsabilidad general en orden a la prevención de los delitos pueda llegar a involucrarlo a tal extremo en las consecuencias dañosas que ellos produzcan con motivo de hechos extraños a su intervención directa.

10.- Tampoco es posible establecer que una declaración inmediata de estado de excepción constitucional el mismo día 27 de febrero de 2010 hubiere impedido la secuencia de saqueos acontecida en la comuna de San Pedro de la Paz y en las comunas que conforman el Gran Concepción, más aún si ellos se iniciaron pocas horas después del terremoto y maremoto.

11.- No es posible determinar en autos, atendida la anormalidad de la situación fáctica imperante en la zona de catástrofe, que la omisión o retardo en la declaración de estado de excepción operara como una condición determinante en la producción del daño. Son los actos de violencia colectiva, generalizados en la zonas afectadas por el terremoto, los que han ocasionado el daño que refieren los actores; de modo que la vinculación externa y material que enlaza el evento dañoso con el retardo en declarar el estado de excepción constitucional para el Bio-Bio se encuentra ausente.

12.- Tampoco era posible prever razonablemente que la población de distintas zonas, de diversos estratos sociales, edades, sexo y condiciones fueran en forma masiva a proveerse mediante saqueos a locales comerciales de bienes para su propia utilidad, aprovechando la situación de calamidad pública que imperaba"1.

1 La sentencia de primera instancia desestima que se haya producido falta de servicio atendido el contenido del servicio de seguridad que puede otorgar el Estado, cuestión que afecta igualmente la relación de causalidad entre los hechos atribuidos a la Administración del Estado y los daños producidos, señalándose: "DÉCIMO OCTAVO: Que como ya se indicara en este fallo, la noción de falta de servicio se refiere a la de los funcionarios públicos en el ejercicio de sus funciones, por no cumplir sino de una manera irregular las obligaciones legales que les están impuestas. En otras palabras quien contrae la obligación de prestar un servicio lo debe realizar en condiciones adecuadas para llenar el fin para el que ha sido establecido, y es responsable de los perjuicios que causare su incumplimiento o ejecución irregular. 


\title{
3.3. Principio de legalidad y competencia en las decisiones acerca de una calamidad pública
}

\author{
En sus "considerandos resolutivos", la sentencia de casación fondo cita prime- \\ ramente las normas legales que regulan las medidas a adoptar en caso de sismo \\ o catástrofe, que se estimarían como infringidas por parte de los recurrentes, \\ señalándose:
}

Corresponde tener especialmente en cuenta que la responsabilidad basada en la falta de servicio exige una apreciación en concreto de los hechos que se imputan a la administración, que ha de tomar en cuenta la naturaleza de la actividad, los medios de que dispone el servicio, el lazo que une a la víctima con el servicio y el grado de previsibilidad del daño. Dicho con otras palabras, no se trata de un juicio sobre la conducta de los agentes sino sobre la prestación del servicio. En este aspecto resulta relevante diferenciar las acciones de las omisiones, y respecto de este último supuesto corresponde distinguir entre los casos de omisiones a mandatos expresos y determinados en una regla de derecho, en los que puede identificarse una clara falta del servicio, de aquellos otros casos en los que el Estado está obligado a cumplir una serie de objetivos fijados por la ley sólo de un modo general e indeterminado, como propósitos a lograr en la mejor medida posible.

En este sentido, el servicio de seguridad no está legalmente definido de modo expreso y determinado, y mucho menos se identifica con una garantía absoluta de que los ciudadanos no sufran perjuicio alguno derivado de la acción de terceros, por lo demás no es razonable que el Estado sea obligado a que ningún habitante sufra daños de ningún tipo, porque ello requeriría una previsión extrema que sería no sólo insoportablemente costosa para la comunidad, sino que haría que se lesionaran severamente las libertades de los mismos ciudadanos a proteger.

Como conclusión, no puede afirmarse, como lo pretende el actor, que exista un deber de evitar todo daño, sino en la medida de una protección compatible con la tutela de las libertades y la disposición de medios razonables.

DÉCIMO NOVENO: Que los hechos admitidos en este fallo como ciertos se desarrollaron bajo peculiares circunstancias, en un estado de conmoción interior producto de un megasismo, con caída total de las comunicaciones y con la fuerza policial y carabineros dedicada, en las primeras horas, a ubicar y rescatar personas atrapadas, lesionadas y recuperar cuerpos de fallecidos.

Bajo tales peculiares condiciones no pueden calificarse como tardias las decisiones de la autoridad, cuando se advierte que a pocas horas de acaecido el terremoto se habia declarado zona de catástrofe y al día siguientes, 28 de febrero de 2010, estado de excepción constitucional de catástrofe, todo ello en cumplimiento a la normativa Constitucional y Orgánica Constitucional que se ha hecho referencia en el considerando décimo séptimo. Asimismo, cabe considerar que, como aparece del Oficio de fojas 321, que el mismo día 27 de febrero de 2010, existía personal desplegado en la zona que fue incrementándose en los días posteriores y además, de lo que aparece en el informe de fojas 216 un número suficiente de funcionarios policiales para resguardar la comunidad y sus bienes en condiciones de normalidad. En efecto, una decisión como la declaración de estado de excepción constitucional, que importa la restricción y limitaciones de los derechos y libertades que garantiza la Constitución Politica de la República a los ciudadanos, no podía sino adoptarse una vez verificadas los presupuestos reales o aproximados -al menos- de la situación en la zona, no sólo relativos al orden y seguridad, sino también a sus comunicaciones, vías de acceso, número de víctimas, edificios destruidos, efectivos policiales y de Carabineros disponibles, etc. Una restricción de derechos y libertades personales evidentemente no puede ser una decisión apresurada, sino que se impone que sea evaluada, ponderada y coordinada. La mera existencia de un poder o atribución que le corresponde ejercer al Presidente de la República no resulta suficiente para atribuirle responsabilidad en un evento en el cual ninguno de sus órganos o dependencias tuvo participación, toda vez que no parece razonable pretender que su responsabilidad general en orden a la prevención de los delitos pueda llegar a involucrarlo a tal extremo en las consecuencias dañosas que ellos produzcan con motivo de hechos extraños a su intervención directa". 
"Quinto: Que el error de derecho planteado conduce a determinar, en sintesis, si la Ley No 16.282 faculta al Presidente de la República para disponer en el decreto supremo que señale una zona afectada por sismos o catástrofes la medida de intervención de las Fuerzas Armadas para restablecer el orden público; y si su intervención como efecto de la declaración del estado de excepción constitucional de catástrofe por calamidad pública fue dispuesta de manera tardía.

Sexto: Que la Ley No 16.282, publicada en el Diario Oficial el 28 de julio de 1965, que fija disposiciones para casos de sismos o catástrofes, cuyo Titulo I fue refundido, coordinado y sistematizado por el Decreto Supremo No 104 de 1977, contiene las siguientes normas que el recurrente ha estimado infringidas:

El artículo $1^{\circ}$ preceptúa que: 'En el caso de producirse en el país sismos o catástrofes que provoquen daños de consideración en las personas o en los bienes, el Presidente de la República dictará un decreto supremo fundado, señalando las comunas, localidades, o sectores geográficos determinados de las mismas, que hayan sido afectados, en adelante, zonas afectadas...'

A su turno el artículo $3^{\circ}$ mandata: 'El Presidente de la República podrá, por decreto supremo fundado, dictar normas de excepción del Estatuto Administrativo, de las leyes orgánicas de los servicios públicos, de instituciones autónomas o semifiscales, para resolver los problemas de las zonas afectadas o hacer más expedita la ayuda a los países afectados por un sismo o catástrofe.

Las normas de excepción que se autoriza dictar por la presente ley, sólo podrán ejercitarse en los siguientes casos:

a) Designación de autoridades y determinación de sus atribuciones o facultades'.

g) Disponer las comisiones de servicio al extranjero de empleados públicos, de instituciones autónomas o semifiscales, de las Fuerzas Armadas o del Cuerpo de Carabineros; a quienes se les proporcionará, a la brevedad, los medios necesarios para llevar a cabo su cometido'.

Por último, el artículo 20 señala: 'Los Ministros del Interior y de Defensa Nacional elaborarán un plan tendiente a obtener que las Fuerzas Armadas y el Cuerpo de Carabineros desarrollen un programa que abarque los siguientes puntos:

1.- Preparar un plan orgánico para las emergencias que se produzcan a consecuencia de sismos o catástrofes.

2.- Programar la coordinación de los recursos humanos y materiales de los servicios públicos $y$ de las instituciones asistenciales públicas y privadas, para los casos a que se refiere esta ley, $y$

3.- Informar a las autoridades competentes de los problemas críticos que deben ser objeto de medidas preventivas. 
De acuerdo a las normas invocadas, la sentencia concluye que en caso de ocurrencia de sismo o catástrofe, la ley contempla la intervención de diversos órganos del Estado, los que operan en diversos niveles, cada uno con un grado de competencia determinado. En el caso de las Fuerzas Armadas, no se considera la intervención de las mismas en funciones relacionadas con el orden público, a diferencia de lo que ocurre con el estado de excepción constitucional:

"Octavo: Que de acuerdo a las disposiciones transcritas de la Ley No 16.282 y ciertamente de todos sus preceptos aparece que dicho cuerpo normativo regula la intervención de distintos organismos del Estado con motivo de sismos o catástrofes que provoquen daños de consideración en las personas o bienes, con competencias delimitadas. Por otra parte, las funciones de esos entes se orientan a realizar actividades de colaboración y coordinación en la prevención y reacción de los efectos de los sismos o catástrofes, encontrándose las mismas a cargo del Ministerio del Interior. Dicho lo anterior, surge con claridad que el articulo 20 de la Ley-antes transcrito- tiene relación con esa labor preventiva, para lo cual se dota a los Ministerios del Interior y de Defensa de la atribución de elaborar y desarrollar un plan orgánico para las emergencias asi como la programación de la coordinación de los recursos humanos y materiales de los servicios públicos y de las instituciones asistenciales y la evaluación de los problemas criticos que deban ser objeto de medidas preventivas.

Noveno: Que entonces, conforme al claro sentido de las normas de la Ley No 16.282, es evidente que la participación de la autoridad militar se encuentra limitada a la ejecución de las actividades de coordinación determinadas por la autoridad civil y subordinada a la misma, sin que pueda en caso alguno bajo el amparo de ese texto legal velar por el orden público, función que naturalmente puede importar la afectación del ejercicio de los derechos constitucionales. Precisamente esa es una de las diferencias que distinguen a dicha normativa del régimen de estado de excepción constitucional de catástrofe por calamidad pública en el cual la autoridad civil se subordina a autoridad militar del Jefe de Defensa Nacional que debe nombrar el Presidente de la República en lo concerniente a las materias señaladas en la Ley Orgánica Constitucional de Estados de Excepción $N^{o}$ 18.415. Es ilustrativo citar el siguiente párrafo: 'Debe tenerse presente que, en la práctica, desde 1990, cuando se han declarado estados de catástrofe, el Presidente de la República lo ha hecho en virtud de la Ley $N^{o}$ 16.282, no designándose un Jefe de la Defensa Nacional, sino que a civiles de su confianza, a cargo de la zona, eludiéndose la disposición constitucional -obligatoria en esta materia- que ha sido transformada en facultativa, por el artículo $6^{\circ}$ de la Ley $N^{o} 18.415$ Orgánica Constitucional de los Estados de Excepción' (Revista Ius Et Praxis, Miguel Ángel Fernández González, versión online ISSN 0718-0012)".

Del razonamiento anterior, que limita la competencia de los diversos órganos de la Administración del Estado, se concluye que no existía habilitación legal para 
destinar a las Fuerzas Armadas a labores de seguridad pública, de la forma en cómo lo exigen los demandantes, siendo improcedente realizar una interpretación extensiva de estas normas competenciales, señalándose en el considerando décimo de la sentencia:

"En efecto, el Presidente de la República conforme al tenor de las disposiciones de la Ley $N^{o} 16.282$ carece de la competencia, habilitación o autorización para disponer la intervención de las Fuerzas Armadas para los efectos pretendidos por el recurrente. Por el contrario, atenta contra el principio de legalidad que emana de los artículos $6^{\circ}$ y $7^{\circ}$ de la Carta Fundamental inferir que posee dicha atribución fundado en una interpretación extensiva o analógica. A este respecto se ha señalado reiteradamente por la jurisprudencia que 'Las facultades que se entregan a la administración tienen por esencia una naturaleza excepcional, y no puede ser extendida su aplicación más allá de lo estrictamente permitido...' 'Constitución Politica de la República de Chile sistematizada con jurisprudencia", Mario Verdugo Marinkovic, Director. Abeledo Perrot, LegalPublishing Chile, 2011, p. 25). En el mismo sentido, Jorge Bermúdez Soto indica: 'Dentro de la competencia, hay elementos que lo integran, como son la materia, el territorio, la cuantía, el grado. Si se produce la violación o infracción de alguno de estos elementos, se produce el vicio que da origen a la nulidad del acto, denominada exceso de poder' (Derecho Administrativo General, AbeledoPerrot, LegalPublishing Chile, Thomson Reuters, segunda edición actualizada, p. 324).

En suma, por razones de competencia no pudo obrar la autoridad política de la manera pretendida por el recurrente. Tampoco se justifica otra conclusión basada en una interpretación finalista, determinada por la aceptación del ejercicio del poder-ante una situación de emergencia-por una parte significativa de la sociedad, por cuanto en ese mismo sentido la interpretación debe respetar tanto las garantías y derechos constitucionales como las autoridades del Estado que en situaciones de excepción ha establecido el ordenamiento juridico para hacer frente a dichos acontecimientos.

Por consiguiente, al decidir de la manera que lo hizo el fallo impugnado no ha incurrido en infracción a las disposiciones de la Ley No 16.282".

3.4. Falta de servicio y acto de gobierno: acerca de la decisión sobre el estado de excepción

Respecto de la falta de servicio por no haber declarado en lo que los demandantes consideran tiempo oportuno, el estado de excepción constitucional, la sentencia comienza definiendo el mismo, en cuanto a su naturaleza, causales y efectos, señalando:

"Undécimo: Que ahora cabe referirse a las infracciones normativas que dicen relación con una eventual responsabilidad por falta de servicio por la declaración extemporánea 
del estado de excepción constitucional de catástrofe por calamidad pública. Sobre esta materia, es pertinente realizar las siguientes afirmaciones a partir de la lectura de las disposiciones de la Constitución Politica y de lo que se ha desarrollado por la doctrina:

1) 'Se garantiza que el ejercicio de los derechos y garantías, que se aseguran en la Carta Fundamental, sólo podrán verse afectados en la medida de que se declaren estos estados de excepción' (...) 'De manera que podemos concluir que el ejercicio de los derechos y las garantías no es inquebrantable, en la misma Constitución existe la posibilidad de que haya momentos en que dichos derechos pueden verse afectados, pero sólo en los casos en que existan emergencias' (Constitución Política de la República de Chile, doctrina y jurisprudencia, Tomo 1, Puntolex, Thomson Reuters, Director Eduardo Aldunate Lizana, año 2009, p. 420).

2) 'En los artículos 41 y 43 inciso $3^{\circ}$ de la Constitución se regula el estado de catástrofe el cual puede ser declarado por el Presidente de la República en los casos en que se haya producido un hecho de la naturaleza como, por ejemplo, inundaciones, terremotos, sequias, etc., o cuando sea un hecho provocado por el hombre que cause graves daños como un accidente en un reactor nuclear que contamine la atmósfera' (...) 'Su causal es el hecho de que haya producido algún hecho de la naturaleza como un terremoto, sequias, inundaciones, etc., o también por acciones del hombre que causen un daño grave. Puede ser declarado para la zona afectada o para cualquier otra zona que a consecuencia de la calamidad pública asi lo requiera, por lo tanto, se puede decir que no afecta a todo el territorio nacional, sino que a sólo una parte de él. En tanto, en virtud de esta declaración el Presidente de la República queda autorizado para restringir la circulación de las personas y transporte de mercaderías, de reunión; requisar bienes, etc. Y establecer limitaciones al derecho de propiedad y, en general, adoptar todas las medidas administrativas que sean necesarias para el pronto restablecimiento de la normalidad de la zona que se ha visto afectada (...) De manera que podemos concluir que la declaración del estado de catástrofe debe ser declarada por el Presidente de la República, quien tiene la obligación de cumplir con los requisitos exigidos por la Constitución, asimismo, durante el estado de catástrofe el Presidente tiene la facultad de adoptar diversas medidas extraordinarias con el fin del pronto restablecimiento de la normalidad en la zona perjudicada y las zonas respectivas que hayan sido afectadas por la declaración, quedarán bajo la dependencia inmediata del Jefe de la Defensa Nacional que el Presidente designe" (pp. 424 y 425 de la obra citada).

3) Su efecto más importante entonces es que declarado el estado de excepción constitucional de catástrofe, las zonas respectivas quedarán bajo la dependencia inmediata del Jefe de la Defensa Nacional que designe el Presidente de la República.

4) Los tribunales de justicia no podrán calificar los fundamentos ni las circunstancias de hecho invocadas por la autoridad para decretar los estados de excepción. Es una facultad exclusiva del gobierno, de modo que no queda sometida al control jurisdiccional la apreciación del mérito de los antecedentes que han debido considerarse para adoptar la medida". 
En consecuencia, se concluye que la calificación del estado de excepción es un acto de gobierno o político proveniente de una atribución exclusiva de un órgano supremo del Estado que queda exento de control judicial, por expresa disposición constitucional, cuestión que se funda en que el control judicial tiene como límite los actos que son propios de la actividad política, esfera que escapa a los tribunales de justicia. Al respecto la sala constitucional de la Corte Suprema señala:

"Duodécimo: Que la consecuencia inevitable de las aseveraciones precedentes es que, tal como lo señala la juez de la causa, la regulación de los estados de excepción implica la concurrencia de exigencias cuya verificación es de resorte exclusivo del gobierno. En efecto, la Constitución Politica manda sin equivocos que se excluye rotundamente del control judicial el acto administrativo dictado en ejercicio de la potestad de gobierno y discrecional relativa a la declaración de estados de excepción constitucionales, la cual no es susceptible de ser fiscalizada por los Tribunales. Ello tiene como fundamento no sólo la disposición expresa constitucional sino que también la circunstancia de que el control jurisdiccional tiene como límite divisorio los actos que son propios de la actividad política, en este caso de la autoridad máxima de gobierno, de suerte que los órganos jurisdiccionales no se encuentran autorizados para revisar decisiones de esta indole".

En virtud de las consideraciones relacionadas con la competencia del presidente de la República y de las instituciones armadas y respecto de la falta de servicio por no haberse decretado a tiempo el estado de excepción constitucional, la sentencia rechaza el recurso de casación interpuesto y confirma las sentencias de primer y segundo grado que rechazaron la acción interpuesta.

\section{PREVENCIÓN}

El Abogado Integrante Emilio Pfeffer U. formula una prevención a la sentencia, profundizando en la no justiciabilidad del acto político o de gobierno, concurriendo a la decisión de desechar el recurso, señalando que no comparte lo señalado en los considerandos $8^{\circ}, 9^{\circ}$ y $10^{\circ}$ de la sentencia, puesto que ahí se concluye que el presidente de la República no está facultado para disponer que las Fuerzas Armadas se avoquen a labores de orden público, por cuanto tanto la declaración de zona afectada por sismo como la declaración de estado de excepción forman parte de las atribuciones exclusivas y privativas del presidente de la República, que escapan al control jurisdiccional, por tanto el control trastocaría el principio de separación de funciones establecido por la Constitución. Es la prevención reflejo de un cierto clasicismo constitucional anclado en el dogma trinitario de separación de poderes y del cual aún se hace eco el artículo $4^{\circ}$ del 
Código Orgánico de Tribunales, de suerte que el Poder Judicial no podría interferir con actos o decisiones de otros poderes del Estado. Consigna la prevención del abogado integrante:

"Se previene que el Abogado Integrante Sr. Pfeffer concurre al rechazo de la impugnación sin compartir los fundamentos que se expresan en los motivos octavo, noveno y décimo, en tanto en ellos se concluye que la Ley $N^{o} 16.282$ no faculta al Presidente de la República para disponer la medida de intervención de las Fuerzas Armadas para restablecer el orden público en una zona que un decreto supremo declare fue afectada por sismos o catástrofes.

No es tal, a juicio de éste previniente, la razón que debe conducir al rechazo del arbitrio en este punto, desde que la declaración de la Región del Bio-Bio como zona afectada por el sismo con características de terremoto el mismo día 27 de febrero de 2010 se inscribe, al igual que la declaración del estado de excepción constitucional de catástrofe, en el ámbito de las atribuciones exclusivas del Presidente de la República.

La decisión de declarar por medio del decreto supremo respectivo a las zonas de Valparaíso, del Libertador Bernardo O'Higgins, del Maule, del Bío-Bío, de La Araucanía y Metropolitana como afectadas por la catástrofe derivada de un sismo con características de terremoto importa el ejercicio de una atribución exclusiva y privativa de la autoridad politica que escapa al control jurisdiccional.

Admitir que una decisión tal, en esencia un acto politico o de gobierno, no justiciable, pueda ser evaluado en su mérito por la judicatura trastoca el principio de separación de funciones desde que abre cauce a un control en sede jurisdiccional que la Constitución Politica entrega explícitamente a órganos politicos.

Ponderar si debia declararse zona de catástrofe a alguna región del pais en ejercicio de las facultades que al Presidente de la República le otorga la Ley No 16.282, si una declaración tal fue tardía o si ésta debió comprender la medida de convocar a las Fuerzas Armadas es una atribución privativa y excluyente del Ejecutivo que la judicatura no puede subrogar. $Y$ tal es precisamente lo que ocurriría si esta Corte Suprema se avoca a esas determinaciones que en nuestra institucionalidad quedan sujetas al control politico".

\section{DisidenCIA: LOS CAMINOS DEL "GARANTISMO"}

La sentencia fue acordada con el voto en contra del Ministro Sergio Muñoz G., presidente de la sala constitucional y actual presidente del Supremo Tribunal, quien estuvo por acoger el recurso de casación y, por tanto, en la decisión correlativa hacer lugar a la demandan interpuesta.

El voto disidente parte señalando que está de acuerdo con que, conforme a la Ley No 16.282, sólo pudo destinarse a los órganos militares a actividades de 
colaboración con la autoridad civil, señalando luego que ante el terremoto y maremoto acaecidos el día 27 de febrero de 2010, la autoridad tenía la obligación de adoptar todas las medidas extraordinarias para superar las circunstancias que eran igualmente extraordinarias, concluyéndose que el acto administrativo que declaró las zonas respectivas como afectadas por el sismo contiene una omisión que resulta ser significativa, a saber, la participación de las Fuerzas Armadas en las labores que les resultaban propias. Esta omisión es la base de la responsabilidad estatal, pues configura un defectuoso funcionamiento del servicio, dado que las medidas adoptadas fueron insuficientes, lo que provocó la producción de los daños que son reclamados por los demandantes. En suma, el camino garantista niega toda posibilidad a las inmunidades del poder, en la medida que la tutela de los derechos y el alto estándar exigido a la Administración se sobreponen a la imprevisibilidad y profundidad de una catástrofe y a las decisiones políticoinstitucionales del gobierno. El disidente destaca:

“4) Que no obstante la oportuna dictación del Decreto Supremo No 150 que señala como zona afectada por el sismo con características de terremoto la Región del Bio-Bío el mismo día 27 de febrero de 2010, éste contiene una omisión significativa: no se dispuso perentoriamente que las Fuerzas Armadas participaran en las actividades propias de colaboración que le facultaba la Ley $N^{o} 16.282$.

$5^{\circ}$ Q Que dicha omisión importa un defectuoso funcionamiento del servicio, por cuanto ante el acaecimiento de una situación de excepción, en que se constataba una grave afectación de la propiedad de las personas por los hechos de la naturaleza, se unieron los continuos saqueos, debido a lo cual necesariamente debió incluirse la participación inmediata de las Fuerzas Armadas en los términos antes indicados en el referido Decreto Supremo $N^{o} 150$, dado que natural y razonablemente ello habría importado el restablecimiento más oportuno de la normalidad. En consecuencia, resulta ineludible concluir que en la especie hubo incumplimiento de los deberes de servicio contenidos en la ley. En efecto, el Servicio demandado dotado en la regulación de la Ley $N^{o} 16.282$ para mandatar a las Fuerzas Armadas para los efectos indicados, no las incorporó en el acto administrativo aludido, adoptando en cambio medidas insuficientes que no fueron capaces de resistir ni previeron la presión ejercida por personas en condiciones de caos que produjeron la afectación de los bienes de los actores. En efecto, si bien los hechos de la naturaleza, en principio podrian presentar elementos que no lo hacen predecibles con facilidad, la reiteración de estos hechos con cierta periodicidad en nuestro pais deben llevar a la autoridad a considerar un plan de acción, como tener previstas las vías para prevenir mayores males a la ciudadania, en la cual no deben medirse los esfuerzos, todo lo contrario, la mayor colaboración es la recomendación que se impone en tales circunstancias.

$6^{\circ}$ ) Que en suma ha quedado establecido que la insuficiencia de las medidas adoptadas en el Decreto Supremo No 150 fue condición suficiente y necesaria en la producción 
de los daños ocasionados a los locales comerciales de los actores, teniendo en cuenta que es un hecho de la causa que el personal disponible de las Fuerzas Armadas en la zona afectada era considerable, de modo que al menos pudo acarrear con alta probabilidad un efecto disuasivo en la perpetración de los hechos ilicitos contra la propiedad. Además no se puede desconocer las condiciones de desprotección en que quedan las personas, sus propiedades, especialmente los más afectados por los efectos del hecho de la naturaleza como es el terremoto y maremoto o tsunami.

$\left.7^{\circ}\right)$ Que por lo expresado, se ha producido error de derecho por falta de aplicación de las normas contenidas en la Ley $N^{o}$ 16.282, por cuanto una adecuada interpretación de carácter teleológico de sus preceptos importaba concluir que en ellos subyace la idea matriz de asegurar la tranquilidad y paz social requerida por los ciudadanos en una situación excepcional. Desde luego, esas finalidades, no implicaban necesariamente la restricción de los derechos fundamentales de las personas, por cuanto es posible inferir razonablemente que la sola presencia del personal militar habría contribuido de un modo significativo con la mantención del orden público. Por lo tanto, la autoridad civil que tenía a cargo la conducción de ese personal bajo el amparo de la Ley $N^{o} 16.282$, y que había identificado los factores que determinaban las condiciones de inseguridad, debió actuar de manera coordinada e integrada con las Fuerzas Armadas para prevenir y controlar dichos factores, de tal forma de asegurar, en el sector afectado, un apropiado nivel de seguridad para sus habitantes, todo lo cual no hizo en relación a los actores".

Luego, el Ministro Muñoz expone una serie de normas administrativas e internacionales referidas al ámbito de actuación de la Administración y las características que dicha actuación debe reunir para considerarse ajustada a derechos, concluyendo que la omisión que se reprocha a la Administración del Estado en estos autos ha provocado que no se cumplieron con los principios orientadores en los que dicha la actividad de dichos órganos debe basarse:

$\left.8^{\circ}\right)$ Que sin perjuicio de lo dispuesto por la Ley $N^{o}$ 16.282, el Decreto con Fuerza de Ley $N^{o} 1$ del Ministerio del Interior, de 8 de noviembre de 2005, que fijó el texto refundido, coordinado y sistematizado y actualizado de la Ley No 19.175, Orgánica Constitucional sobre Gobierno y Administración Regional, dispone en su artículo $1^{\circ}$, que el gobierno interior de cada región reside en el intendente a quien le corresponde, según el artículo $2^{\circ}$, velar porque en el territorio de su jurisdicción se respete la tranquilidad, orden público y resguardo de las personas y sus bienes (letra b), requerir el auxilio de la fuerza pública en conformidad a la ley (letra c), ejercer la coordinación, fiscalización o supervigilancia de los servicios públicos creados por ley para el cumplimiento de la función administrativa, que operen en la región (letra j), adoptar todas las medidas necesarias para prevenir y enfrentar situaciones de emergencia o catástrofe (letra $\tilde{n}$ ), dictar las resoluciones e instrucciones que estime necesarias para el ejercicio de sus atribuciones (letra o) y cumplir las funciones que le asignen las leyes (letra p). 
Por su parte el Decreto con Fuerza de Ley No 1/19.653, del Ministerio Secretaría General de la Presidencia, de 17 de noviembre de 2001, que fija el texto refundido, coordinado y sistematizado de la Ley No 18.575, Orgánica Constitucional de Bases Generales de la Administración del Estado, dispone que la Administración del Estado se encuentra constituida por los Ministerios, Intendencias, los órganos y servicios públicos creados para el cumplimiento de la función administrativa, incluidas las Fuerzas Armadas y las Fuerzas de Orden y Seguridad Pública y las empresas públicas creadas por ley (artículo $1^{\circ}$ inciso segundo), la cual deberá observar los principios de responsabilidad, eficiencia, eficacia, coordinación y control, entre otros (artículo $3^{\circ}$ ). Es asi como las autoridades y funcionarios deberán velar por la eficiente e idónea administración de los medios públicos y por el debido cumplimiento de la función pública, así como los órganos de la Administración del Estado deberán cumplir sus cometidos coordinadamente y propender a la unidad de acción, evitando la duplicación o interferencia de funciones (artículo $5^{\circ}$ ). Es por ello que, destacando la vinculación de tal normativa y su imperativo cumplimiento, el artículo 62 dispone que se contraviene especialmente el principio de probidad administrativa el no observar los deberes de eficiencia, eficacia y legalidad que rigen el desempeño de los cargos públicos, con grave entorpecimiento del servicio o del ejercicio de los derechos ciudadanos ante la Administración (numeral octavo).

En el mismo sentido se pronuncia el Estatuto Administrativo, al establecer la prohibición de someter a tramitación innecesaria o dilación los asuntos entregados a su conocimiento y resolución (articulo 84, letra e).

Por su parte el Pacto Internacional de Derechos Civiles y Politicos dispone que el derecho de asociación podrá ser sujeto a restricciones legales, necesarias en una sociedad democrática, en interés de la seguridad pública o de orden público, o para proteger la salud o la moral públicas o los derechos y libertades de los demás incluyendo en las posibles restricciones a los miembros de las Fuerzas Armadas y de la policía (artículo 22).

De todo lo anterior surgen las obligaciones que imponen brindar un servicio público a la Administración de manera ágil, eficiente, efectiva, coordinada y de excelencia, en que la seguridad, salubridad y tranquilidad de la población esté resguardada, circunstancia que no se produjo en la especie y de lo cual derivó en daños respecto de los actores, los que corresponde indemnizar".

\section{Conclusiones}

La sentencia comentada en la perspectiva del Derecho público (constitucional y administrativo) plantea dos cuestiones centrales: la falta de servicio como título de imputación y el acto de gobierno como atribución no susceptible de control judicial, todo a propósito de hechos dañosos provocados por acción de terceros 
(saqueos y delitos contra la propiedad) en comunas de la VIII Región con motivo del terremoto y maremoto del 27 de febrero de 2010.

El telón de fondo es la coexistencia de dos estatutos en nuestro ordenamiento frente a catástrofes naturales, estatutos especiales y excepcionales, pero de muy distinto alcance ${ }^{2}$.

Primero, el derecho de excepción que prevé "estados de excepción” para las hipótesis o "situaciones": guerra externa o interna, conmoción interior, emergencia y calamidad pública; las que dan origen a los estados siguientes: asamblea, sitio, emergencia y catástrofe (artículos 39 a 45 de la Constitución y Ley No 18.415 orgánica constitucional del rubro) ${ }^{3}$. El derecho de excepción tiene por finalidad la defensa extraordinaria del Estado nación, para lo cual se establecen ciertos estados o regímenes especiales que permiten la adopción de medidas que afectan los derechos fundamentales y sus garantías, todo con sujeción a ciertos estándares básicos incorporados en parte con la reforma constitucional de 2005 a la Constitución vigente, a saber: temporalidad, provisionalidad, racionalidadproporcionalidad y justiciabilidad de las medidas que se adopten al amparo de tales Estados. Invariablemente la decisión acerca del estado de excepción es política (Schmitt) ${ }^{4}$; intervienen los poderes constituidos en su declaración siendo el impulso fundamental del presidente de la República, y precisamente un acto de gobierno es un acto estatal no justiciable, independientemente de su forma un decreto supremo, todo sin perjuicio de los controles políticos o de legalidad que siempre son procedentes 5 .

En este contexto el estado de catástrofe habilita al presidente de la República para "restringir" las libertades de locomoción y de reunión", disponer de requisiciones, establecer limitaciones al ejercicio del derecho de propiedad y adoptar las medidas extraordinarias de "carácter administrativo que sean necesarias para el pronto restablecimiento de la normalidad en la zona afectada". Bajo este estado

2 Ríos Álvarez, Lautaro (2005): Los Estados de Excepción Constitucional en una perspectiva humanista, en Nogueira Alcalá, Humberto (Coordinador): La Constitución Reformada de 2005, Libro Colectivo (Santiago, Editorial Librotecnia), pp. 319-344.

3 Zúñiga Urbina, Francisco. Libertad y Autoridad en el Derecho Constitucional: el Derecho de Excepción, XXXIII Jornadas de Derecho Público, Universidad de Concepción.

4 García Pino, Gonzalo (2005): Los Estados de Excepción Constitucional: un Nuevo Derecho de Excepción, en Zúniga Urbina, Francisco (Coordinador): Reforma Constitucional, Libro Colectivo (Santiago, Editorial LexisNexis), pp. 451-476.

5 Cordero Quinzacara, Eduardo (2005): La Facultad Fiscalizadora de la Cámara de Diputados". En op. cit., pp. 507-526. 
de excepción, las facultades conferidas al jefe de Estado podrán ser delegadas total o parcialmente a los jefes de la Defensa Nacional (art. $6^{\circ}$ Ley No 18.415).

El fin común de los estados de excepción es la defensa extraordinaria del Estado nación frente a una situación de anormalidad que afecte "gravemente el normal desenvolvimiento de las instituciones del Estado", y para ello la seguridad y orden públicos son bienes constitucionales valiosos a restablecer. En la guarda de la seguridad y el orden público como bienes valiosos excepcionalmente las Fuerzas Armadas intervienen en estos casos de excepción y en el resguardo del orden durante actos electorales y plebiscitarios (artículo 18 inciso final de la Constitución), todo sin perjuicio de las tareas institucionales bajo situación de normalidad que le compete a la fuerza pública (Carabineros de Chile y Policía de Investigaciones).

En cambio y en segundo lugar, la Ley No 16.282 es un estatuto especial para sismos y catástrofes (aluviones, sequías prolongadas o pluviometría prolongada, heladas o erupciones volcánicas, entre otras) cuya finalidad es disponer de medidas administrativas extraordinarias y sin sujeción al derecho común administrativo para proveer bienes y servicios públicos con prontitud, eficiencia e idoneidad a la población o zona afectada.

En consecuencia, se trata de estatutos que difieren radicalmente en sus fines aunque puedan ser empleados simultáneamente, para conservar la seguridad y orden público (anormalidad) y para asistir a la población damnificada con el sismo o catástrofe.

De esta manera la decisión del presidente de la República, cabeza del gobierno y de la Administración, de recurrir a las Fuerzas Armadas que son parte de la Administración estatal tiene en ambos estatutos fines diversos.

Por otra parte, decisión de declarar un estado de excepción es un acto político o de gobierno del presidente de la República, consagrado como "atribución especial” (artículo 32 No 5 de la Constitución), con el concurso de otros poderes instituidos cuando fuere menester, no siendo controlable judicialmente, ya que los tribunales de justicia "no podrán calificar los fundamentos ni las circunstancias de hecho invocadas por la autoridad" (artículo 45 de la Constitución), todo sin perjuicio de lo dispuesto en el artículo 39, disposición que es adicionada por la reforma constitucional de 2005 y que busca reforzar la finalidad del estado de excepción: conservar la normalidad de las instituciones ${ }^{6}$.

6 Pfeffer Urquiaga, Emilio (2002): "Estado de Excepción Constitucional y Reforma Constitucional”, en Revista Ius et Praxis, No 1, Año 8, Universidad de Talca, p. 242. También FernÁndez, Miguel Ángel (2002): "Estados de Excepción, Reformas Constitucionales", en Revista Ius et Praxis, No 1, Año 8, p. 220. 
En consecuencia, parece conforme a nuestro orden constitucional distinguir radicalmente entre el derecho de excepción y los estados de excepción, y el estatuto especial de la Ley No 16.282. La seguridad y orden público como bienes valiosos a conservar para asegurar el normal desenvolvimiento de las instituciones es el que habilita a hacer uso de las Fuerzas Armadas en tareas propias de la administración policial.

Con estas precisiones podemos abordar las definiciones sobre falta de servicio y acto de gobierno de la sentencia comentada. Sobre la falta de servicio nuestra doctrina y jurisprudencia tiene al día de hoy un desarrollo satisfactorio, y sobre su concepto nada nuevo tenemos en cuanto título de imputación que supone una acción reprochable que proviene de la mala organización administrativa o del funcionamiento defectuoso de los servicios públicos.

En consecuencia, lo nuevo en la doctrina jurisprudencial es el estándar "de comportamiento" exigible a la Administración (Letelier) frente a catástrofes naturales, y estamos de acuerdo con el esquema explicativo propuesto por el autor para definir tal estándar en razón de que la respuesta estatal frente a desastres naturales es siempre limitada: i) ante la continua necesidad de satisfacer necesidades públicas es una decisión racional preferir aquellas más urgentes y cuyos requerimientos son permanentes; ii) desastres a gran escala son muy difíciles de manejar principalmente en las primeras horas de ocurrido el hecho y luego de ello dependiendo del grado de destrucción acontecido, y iii) el desastre natural, en tanto evento de fuerza mayor, o bien excluye la relación de causalidad o bien incide en la falta de servicio a través de la alteración de las exigencias normales que resultan esperables de un servicio público ${ }^{7}$. Sólo con estos baremos podemos utilizar la falta de servicio como título de imputación y consiguiente responsabilidad patrimonial del Estado. De lo contrario, podríamos argumentar ad absurdum acerca de la seguridad total o el orden total, verdadero reino perdido de alguna utopía totalitaria.

Luego, los argumentos acerca de la previsibilidad de hechos luctuosos con motivo de catástrofes naturales o el supuesto rol disuasivo de las Fuerzas Armadas son una conjetura, ya que la calificación de los fundamentos o las circunstancias de hecho que ameritan la declaración de estado de catástrofe son de resorte de la autoridad (presidente de la República) y la movilización efectiva de las Fuerzas

\footnotetext{
7 Letelier Wartenberg, Raúl (2012): Falta de Servicio en Situaciones de Catástrofes Naturales, en Letelier Wartenberg, Raúl (Coordinador): La Falta de Servicio, Libro Colectivo (Santiago, Editorial AbeledoPerrotThomson Reuters), pp. 303-321.
} 
Armadas a tareas de seguridad y orden público están condicionadas por la magnitud de la catástrofe y su impacto en las comunicaciones.

Bajo estas coordenadas es posible utilizar la falta de servicio como título de imputación, y las limitaciones que resulten de ella, trasladan el problema de la seguridad y orden público a los bienes públicos que el Estado pueda proveer eficientemente y según su capacidad financiera a la población damnificada y afectada en su patrimonio.

Para concluir, sólo resta consignar que la sentencia de casación comentada nos trae una pieza de museo que goza de especial vitalidad en tiempos de activismo judicial: el acto de gobierno o acto político no justiciable; que en un Estado de Derecho moderno tiene un muy reducido espacio, y uno de esos espacios es el derecho de excepción ${ }^{8}$. Con todo, la sentencia comentada delinea de manera completa al acto de gobierno: primero, es un acto fruto de una atribución exclusiva o "especial" del presidente la República, de fuente constitucional (artículo 32 No 5 de la Constitución); segundo concierne a un estatuto excepcional para situaciones de anormalidad que exigen prontamente el restablecimiento de la normalidad institucional (salud pública); tercero la politicidad de la materia incardinada en una subfunción gubernativa del "Poder Ejecutivo"; cuarto, el margen de libre apreciación (impropiamente denominada "discrecionalidad") de la autoridad ejecutiva frente a las hipótesis habilitantes para declarar estados de excepción, y quinto, la inmunidad de control judicial.

Consiguientemente, el acto de gobierno o político de clara filiación francesa, pero que adopta diversas concreciones en el Derecho público comparado, que para muchos es una pieza de museo, un trasto viejo de la batalla contra las inmunidades del poder, no es una pieza oxidada. El acto de gobierno conserva la plasticidad práctica exigida por los gobernantes situados en la sala de máquinas del Estado (el Estado en acción) y el reconocimiento de la doctrina jurisprudencial.

Como hemos sostenido en otra ocasión (en las Jornadas de Derecho Constitucional de las Asociaciones de América del sur en la Universidad Católica Argentina en abril de 2008), la doctrina y praxis del acto de gobierno sigue es-

8 Una exposición maciza, general y "polémica” en el libro de Garrido Cuenca, Nuria (1998): El Acto de Gobierno. Un Análisis de los Ordenamientos Francés y Español (Barcelona, Editorial CEDECS).

Una visión distinta de GARCía de EnTERRía, Eduardo (1998): Democracia, Jueces y Control de la Administración (Madrid, Editorial Civitas, 4a edición). En esta edición ampliada de 1998, García de Enterría se hace cargo de la obra y en un prólogo durísimo arremete contra la tesista y su director Luis Ortega acusándolos de jacobinismo y decisionismo, "espantapájaros" frecuentes por lo demás en obra del recientemente desaparecido maestro del Derecho Administrativo español. 
tando presente en los países con sistemas democráticos. Concluimos ayer y hoy, cuando nos correspondió desarrollar una ponencia sobre el acto de gobierno y su permanencia efectiva en el funcionamiento del Estado, frente a los numerosos inquisidores letrados imbuidos de panjudicialismo para quienes el contralor judicial no tiene límites y es la piedra angular del Estado de Derecho (que no es sino un Estado judicial aquejado de un patológico activismo y gobierno de los jueces incompatible con el orden republicano democrático y el imperio de la ley), "E pur si muove".

\section{Post scriptum. De vueltas al acto de gobierno}

Con posterioridad a la sentencia comentada, la Corte Suprema ha dictado sentencia sobre la reserva de información que recae en los contratos que se celebraron entre el Estado de Chile y los abogados que representaron al país en la Corte Internacional de Justicia de La Haya (Rol No 13.510-2013, sentencia de fecha 13 de enero de 2014). Esta sentencia se dicta en el contexto de un recurso de queja, interpuesto por el Fisco de Chile, que recurrió ante la Corte Suprema, respecto de la sentencia de la Corte de Apelaciones de Santiago (Rol No 46802012) que ordenó al Ministerio de Relaciones Exteriores la entrega de información relativa a los abogados que han representado a Chile en el litigio que se tiene con Perú en la Corte Internacional de Justicia de La Haya, este recurso fue acogido por la Corte Suprema con lo cual se declaró la reserva de la información que había sido solicitada, dejándose sin efecto decisión de amparo del Consejo para la Transparencia (CPLT).

El recurso de queja señala que existen cuatro faltas o abusos que justifican la procedencia del recursos de queja: (i) No considerar la causal de reserva contenida en el artículo 21 No 4 de la Ley de Transparencia, esto es, afectar el interés nacional, pese a que la publicidad de la información pone a Chile en posición de desventaja respecto de Perú; (ii) Que se haya desestimado el deber de reserva contenido en el artículo 42.3 del estatuto de la Corte Internacional de Justicia de La Haya, que decreta la inviolabilidad de todo papel o documento, entre los que se cuenta los contratos de los abogados; (iii) Que se omite el pronunciamiento sobre infracciones al debido proceso por parte del Consejo para la Transparencia, que recibió pruebas de la parte solicitante de información, pero no de la solicitada, ni tampoco dio acceso a tales a pruebas; (iv) Que la Corte de Apelaciones no se pronunció respecto de una de las causales de reserva, a saber, la afectación del debido cumplimiento de las funciones del órgano, contenida en el artículo 21 No 1 de la Ley de Transparencia. 
En su decisión, la Corte Suprema acoge la queja, en base a que los sentenciadores han desatendido el tenor literal de la Constitución y la ley, en la medida que se le entrega al presidente de la República la facultad de conducir las relaciones internaciones de forma privativa, por tanto sólo él puede determinar qué hecho puede afectar dichas relaciones, por lo que la publicidad de la información afecta, en este contexto, el interés nacional, retornando esta magistratura a la doctrina del acto político o de gobierno no justiciable, doctrina abordada con antelación en la sentencia de casación relativa al juicio reparatorio por falta de servicio del Estado con motivo de los delitos afectantes a la propiedad ocurridos con ocasión del terremoto y maremoto de 27 de febrero de 2010. Así consigna el fundamento de la sentencia:

"DÉCIMO TERCERO: Que al desestimar la reclamación de ilegalidad deducida por el Fisco en contra de la Decisión de Amparo Rol No C-1553-11, que otorgó la publicidad pedida, los sentenciadores han vulnerado las normas transcritas, especialmente las de los artículos $32 N^{o} 15$ de la Constitución Política de la República, 21 No 4 de la Ley de Transparencia y 19 del Código Civil, pues resultando claro su sentido y su texto se ha desatendido su tenor literal, con lo que se ha llegado a una declaración enteramente opuesta al mismo que supone una contravención formal de las disposiciones aludidas.

En efecto, la Carta Fundamental y la ley dictada para desarrollar su texto normativo en esta materia disponen de manera clara e inequivoca que es al Presidente de la República como Jefe de Estado en un régimen de tipo presidencial como el nuestro a quien corresponde exclusivamente la conducción de las relaciones internacionales del pais (Alejandro Silva Bascuñán, Tratado de Derecho Constitucional, Tomo V, la Constitución de 1980 "Gobierno", Editorial Juridica de Chile, Santiago, 2004 pp. 84 y ss.) y, por ende, que sólo a él, mediante los organismos estatales establecidos para tal efecto en su representación, cabe calificar si una determinada decisión las afectará, sin que el Consejo para la Transparencia se encuentre capacitado para alterar esa ponderación ni los sentenciadores recurridos cuenten con competencia o legitimación para desatender dicha estimación".

Igualmente, se acoge el segundo capítulo de impugnación, puesto que se arriba a la conclusión de que las normas internacionales que decretan la inviolabilidad de documentos y papeles en la Corte Internacional de Justicia son normas con rango normativo suficiente para decretar la reserva de información:

"DÉCIMO SÉPTIMO: Que debiendo cumplirse en nuestro país la 'Convención general sobre prerrogativas e inmunidades de las Naciones Unidas' como ley de la República, la que se haya actualmente vigente, dictada antes de la promulgación de la Ley $N^{\circ} 20.050$ y que establece en su artículo $I V$ sección 11 'reserva respecto de determinados actos o documentos' fundada en el interés nacional y en el debido cumplimiento de las funciones 
de los órganos estatales involucrados en el litigio de que se trata, se ha de entender que ella cumple con la exigencia constitucional de quórum calificado y que, por ende, en la especie configura una causal de reserva que impide al Estado de Chile dar a conocer la información cuya publicidad ha sido solicitada por Romina Colman Carnevali, motivo por el que al disponer los recurridos la entrega de información sujeta a secreto han incurrido en falta o abuso que amerita el acogimiento del recurso de queja también por este capitulo".

El tercer capítulo de impugnación igualmente se acoge en la especie, puesto que se considera que el Consejo para la Transparencia debió haber abierto un término probatorio, no siendo ello una facultad, sino que una necesidad, a la luz del derecho al debido proceso:

"VIGÉSIMO: Que al respecto se debe consignar que, como lo ha sostenido reiteradamente la jurisprudencia de esta Corte Suprema, el respeto de la garantía del debido proceso, establecida en el artículo $19 N^{\circ} 3$ inciso sexto de la Constitución Política de la República, supone, entre otros deberes para el órgano que conoce del asunto sometido a su decisión, el de recibir el proceso a prueba si es que concurren las circunstancias de hecho que asi lo ameritan, pues cláusulas como la del inciso final del artículo 25 reproducido precedentemente no resultan ser discrecionales para el órgano respectivo. En efecto, no se trata en la especie de que el Consejo para la Transparencia haya estado facultado para, si lo deseaba o lo estimaba apropiado, abrir un término probatorio, pues debe entenderse que la disposición legal apunta a su facultad para disponer de manera oficiosa dicho trámite en el caso de que estén presentes los supuestos fácticos que hacen procedente la recepción del proceso a prueba. En estas condiciones, el Consejo para la Transparencia se hallaba en la necesidad de iniciar la etapa procesal descrita y al no declararlo asi los sentenciadores han incurrido en falta o abuso que justifica el acogimiento del recurso en examen".

Finalmente, la sentencia de la Corte Suprema desestima el último capítulo de impugnación, referido a la falta de pronunciamiento respecto de la causal de reserva consistente en que la publicidad de la información solicitada afecta el debido cumplimiento de las funciones del órgano requerido, esto por cuanto la sentencia de la Corte de Apelaciones de Santiago, en su considerando quinto, señala que no puede tomarse en cuenta la causal puesto que el artículo 28 de la Ley de Transparencia le impide al órgano público interponer reclamación basado en dicha causal.

Por último, la sentencia hace una aclaración, en cuanto a que la condición de los abogados nacionales que participan en el procedimiento ante la Corte Internacional de Justicia no tienen diferencia con los abogados extranjeros, por lo que la información igualmente se encuentra cubierta por la reserva, sin que la conclusión se modifique por la decisión del Ministerio de Relaciones Exteriores de publicar dicha información. 
La sentencia de la Sala Constitucional de la Corte Suprema reviste interés, primero reitera una doctrina jurisprudencial anterior acerca de la reserva que cautela a los abogados en relación a su cliente, que se extiende a las estipulaciones contractuales y, segundo, reitera el especial vigor de la doctrina del acto de gobierno esta vez aplicada a la conducción de las relaciones internacionales por el jefe de Estado y la concurrencia de un interés general justificativo de la reserva o secreto, actuación política irrevisable. Con estos dos argumentos la sentencia de queja se bastaría a sí misma, pero se hace cargo de dos líneas argumentales complejas o erradas en su apreciación a nuestro entender con motivo de la impugnación de queja.

En efecto, la sentencia contiene en su ratio decidendi de queja dos líneas argumentales complejas cuando no erradas al hacerse cargo del segundo y tercer capítulo de impugnación, a saber: extiende la ficción de quórum de la legislación preconstitucional y extiende la garantía del debido proceso a los procedimientos administrativos no contenciosos.

En cuanto a la primera línea argumental: la ficción de quórum de la Disposición Cuarta Transitoria de la Constitución en relación al artículo $8^{\circ}$ que prevé como fuente de la reserva o secreto la ley de quórum calificado, a una Convención general sobre prerrogativas e inmunidades de las Naciones Unidas, configura un yerro evidente, dado que la ficción de quórum necesaria para armonizar un sistema de fuentes que fragmenta la ley se refiere a "leyes" y no a tratados internacionales. Tal evidente yerro dogmático no puede ser ocultado con la afirmación rimbombante del sentenciador en orden a que tal tratado es una "ley de la República".

Por último, la extensión de la garantía del debido proceso legal que hace la sentencia de queja al procedimiento administrativo no contencioso ventilado ante el Consejo para la Transparencia es una extensión compleja y constitucionalmente inadecuada. La garantía del debido proceso legal en nuestro ordenamiento no se extiende a toda potestad pública como garantía innominada del poder público que es el tratamiento anglosajón, sino en rigor tal garantía se predica como un conjunto de estándares protectores vinculantes de la potestad jurisdiccional y de la investigación y que la Ley No 18.575 extiende a procedimientos disciplinarios en su artículo 18 inciso $2^{\circ}$. Cosa distinta son los mecanismos de audiencia y prueba en procedimientos administrativos no contenciosos en que se expresa una potestad administrativa unilateral por el CPLT, revisable en sede jurisdiccional a través del reclamo de ilegalidad del artículo 28 de la Ley de Transparencia y superrevisable a través de la pretoriana queja. Más adecuado habría resultado recurrir a la línea 
argumental plástica del principio de razonabilidad y de proporcionalidad en la usina de la decisión de amparo proveniente del CPLT.

En suma, la sentencia de queja comentada de la Tercera Sala de la Corte Suprema nos deja, excusando la analogía, un sabor agridulce, dado que no siempre se observa la consistencia esperable de esta suprema magistratura, la que debe poner cuidado en el imperio de la ley propia de un Estado de Derecho más aún cuando a un asunto como el fallado subyace la razón de Estado. 